\title{
Reduction of IKK $\alpha$ Expression Promotes Chronic Ultraviolet B Exposure-Induced Skin Inflammation and Carcinogenesis
}

Xiaojun Xia, ${ }^{*}$ Eunmi Park, ${ }^{\dagger}$ Bigang Liu, ${ }^{\ddagger}$ Jami Willette-Brown, ${ }^{\S}$ Wanghua Gong, ${ }^{,}$ Jiming Wang, ${ }^{\S}$ David Mitchell, ${ }^{\ddagger}$ Susan M. Fischer, ${ }^{\ddagger}$ and Yinling $\mathrm{Hu}^{\S}$

From the Center for Cell and Gene Therapy, Baylor College of Medicine, Houston, Texas; the Department of Radiation

Oncology, ${ }^{\dagger}$ Dana-Farber Cancer Institute, Harvard Medical School, Boston Massachusetts; the Department of Carcinogenesis, The University of Texas M.D. Anderson Cancer Center, Smithville, Texas; the Cancer and Inflammation Program, Center for Cancer Research, ${ }^{\Im}$ National Cancer Institute, National Institute of Health, Frederick, Maryland; and the Basic Research Program, "T Science Application International Corporation, Frederick, Maryland

Ultraviolet B light (UVB) is a common cause of human skin cancer. UVB irradiation induces mutations in the tumor suppressor $p 53$ gene as well as chronic inflammation, which are both essential for UVB carcinogenesis. Inhibitor of nuclear factor $\kappa B$ kinase- $\alpha$ (IKK $\alpha)$ plays an important role in maintaining skin homeostasis, and expression of IKK $\alpha$ was found to be down-regulated in human and murine skin squamous cell carcinomas. However, the role of IKK $\alpha$ in UVB skin carcinogenesis has not been investigated. Thus, here we performed UVB carcinogenesis experiments on $I k k \alpha^{+/+}$and $I k k \alpha^{+/-}$mice. I Ikk $\alpha^{+/-}$mice were found to develop a twofold greater number of skin tumors than $I k k \alpha^{+/+}$mice after chronic UVB irradiation. In addition, tumor latency was significantly shorter and tumors were bigger in $I k k \alpha^{+/-}$than in $I k k \alpha^{+/+}$mice. At an early stage of carcinogenesis, an increase in UVB-induced $p 53$ mutations as well as macrophage recruitment and mitogenic activity, and a decrease in UVB-induced apoptosis, were detected in $I k k \alpha^{+/-}$compared with those in $I k k \alpha^{+/+}$skin. Also, reduction of IKK $\alpha$ levels in keratinocytes upregulated the expression of monocyte chemoattractant protein-1 (MCP-1/CCL2), TNF $\alpha$, IL-1, and IL-6, and elevated macrophage migration, which might promote macrophage recruitment and inflammation. Therefore, these findings suggest that reduction of
IKK $\alpha$ expression orchestrates UVB carcinogen, accelerating tumorigenesis. (Am J Pathol 2010, 176:2500-2508; DOI: 10.2353/ajpath.2010.091041)

Ultraviolet B (UVB) irradiation induces DNA damage. The tumor suppressor gene p53 is an UVB target, and human cutaneous squamous cell carcinoma (SCC) cells contain p53 mutations. ${ }^{1}$ Skin cells can harbor UVB-induced p53 mutations for decades before the onset of human SCC, however, ${ }^{2,3}$ underscoring the importance of coactivators in skin tumorigenesis. In mice, p53 mutations are an early genetic event in UVB skin carcinogenesis, which recapitulates the process of human SCC development. ${ }^{4,5}$ The p53 mutations have been proposed to be important for UVB carcinogenesis because prevention of these mutations prevents skin tumor development, and the number of p53 mutation-positive keratinocytes correlates with the number of skin tumors in mice. ${ }^{6-9}$ UVB exposure also induces chronic inflammation, cell proliferation, oxidant stress, and immunosuppression, which essentially facilitate UVB carcinogenesis. ${ }^{10,11}$ Particularly, chronic inflammation can create a microenvironment that is prone to cell proliferation and DNA damage, thereby promoting tumor development. ${ }^{12}$

On the other hand, UVB exposure also elicits protective responses, such as cell cycle arrest, DNA repair, and apoptosis, which reduce UVB-induced damage. ${ }^{7,10,11}$ Previously, it was reported that mice lacking p53 were defective in inducing apoptosis after UVB irradiation and thus had more skin tumors than wild-type mice did. ${ }^{13,14}$ Mice lacking Fas ligand had defects in apoptosis, which increased numbers of cells containing UVB-induced p53 mutations, and the mutant mice were more susceptible to UVB-induced skin tumors than wild-type mice. ${ }^{5,8}$ Therefore, the different

Supported by National Cancer Institute grants CA102510, CA117314 (to Y.H.), and CA105345 (to S.M.F.).

Accepted for publication January 14,2010

Supplemental material for this article can be found on http://ajp. amjpathol.org

Address reprint requests to Yinling Hu, Ph.D., Cancer and Inflammation Program, Center for Cancer Research, National Cancer Institute, National Institute of Health, Frederick, MD 21701. Email: huy2@mail.nih.gov. 
defects in inducing protective responses against UVB-induced damage can amplify the severity of the cancer cause, thereby accelerating carcinogenesis.

Inhibitor of nuclear factor $\kappa \mathrm{B}$ kinase- $\alpha(\mathrm{IKK} \alpha)$ is required for embryonic skin development in mice. ${ }^{15,16} \mathrm{Sev}$ eral laboratories have reported the down-regulated expression and altered localization of IKK $\alpha$ protein as well as deletions and mutations in the $1 k k \alpha$ gene in human SCCs of the skin, lung, esophagus, and head and neck. ${ }^{17-21}$ In particular, IKK $\alpha$ deletion in keratinocytes was found to elevate an autocrine loop activity of epidermal growth factor receptor (EGFR), Ras, extracellular signal-related kinase (ERK), EGFR ligands, and the ligands' activators and induced spontaneous skin SCCs in mice. ${ }^{22}$ Reduction of IKK $\alpha$ expression was found to promote chemical carcinogen-induced skin tumorigenesis. ${ }^{23}$ Also, IKK $\alpha$ is an UVB-induced gene, and the defect in IKK $\alpha$ function was linked to inflammation. ${ }^{24,25}$ UVB is a very common cause of human skin cancer; however, the role of IKK $\alpha$ in skin UVB carcinogenesis is largely unknown. Thus, here we examined the effect of reduced IKK $\alpha$ expression on UVB skin carcinogenesis in $l k k \alpha^{+/-}$and $l k k \alpha^{+/+}$mice. $\mid k k \alpha^{+/-}$mice were significantly susceptible to UVB skin carcinogenesis than were $l k k \alpha^{+/+}$mice. Because the tumor latency was significantly shorter and many more tumors were found in $1 k^{k} \alpha^{+/-}$mice than in $l k k \alpha^{+/+}$mice, we analyzed the early events during UVB skin carcinogenesis. This study provided the first evidence showing the importance of $\mathrm{IKK} \alpha$ in UVB skin carcinogenesis.

\section{Materials and Methods}

\section{Mice and UVB Radiation}

The mice used in this study were cared for in accordance with the guidelines of the Institutional Animal Care and Use Committee of The University of Texas M.D. Anderson Cancer Center (animal protocol 04-01-05732). Ikk ${ }^{+/-}$ mice with a C57Bl6 background were backcrossed with wild-type SKH-1 hairless mice (Charles River Laboratories) for five generations. Female $l k k^{+/-}$and $l k k \alpha^{+/+}$ mice with age of 6 to 8 weeks old that were siblings were UVB-irradiated using Westinghouse FS20 sunlamps in an irradiation chamber (Starch Art). ${ }^{26}$ The broadband range of the UV lamps was 280 to $400 \mathrm{~nm}$, with $80 \%$ of the light in the UVB region and $20 \%$ in the UVA region. For UVB carcinogenesis experiments, mice were irradiated three times a week beginning at a UVB dose of $90 \mathrm{~mJ} / \mathrm{cm}^{2}$ in the first week. This dose was increased by $10 \%$ each week to a maximum of $175 \mathrm{~mJ} / \mathrm{cm}^{2}$. For time-course experiments, mice were UVB-irradiated at $100 \mathrm{~mJ} / \mathrm{cm}^{2}$. Statistic analyses of tumor incidence and multiplicity were done by the statistic core facility at Science Park Research Division, M.D. Anderson Cancer Center.

\section{Assessment of Cell Death, Ki-67 Positive Cell and Macrophage Numbers}

The sunburn cells (SBCs) in the interfollicle epidermis of paraffin-embedded skin sections of mice were stained with hematoxylin and eosin that was performed in the tissue and histology facility of the Department of Carcinogenesis at M.D. Anderson Cancer Center. To count the apoptotic cells, paraffin-embedded skin sections were stained using terminal transferase dUTP nick end labeling (TUNEL) kit (Roche) with immunofluorescence following the manufacturer's manual. Immunohistochemical staining of Ki-67-positive cells and macrophage maker S100A9 in the epidermis of paraffin-embedded skin sections was performed in the tissue and histology facility of the Department of Carcinogenesis at M.D. Anderson Cancer Center. ${ }^{23}$

\section{Radioimmunoassay of DNA Repair}

The number of photoproducts in epidermal DNA of experimental mice was determined using a radioimmunoassay as described previously. ${ }^{26}$ Briefly, DNA $(5 \mu \mathrm{g})$ isolated from mice UVB-irradiated at $100 \mathrm{~mJ} / \mathrm{cm}^{2}$ to induce (6-4)pyrimidine-pyrimidone photoproducts ([6-4]PPs) and cyclobu-pyrimidine dimers was incubated with 5 to $10 \mathrm{pg}$ of poly(deoxyadenylate-deoxythymidylic acid) (labeled to more than 5 times greater $108 \mathrm{cpm} / \mathrm{mg}$ using nick translation with $\left.\left[\alpha^{-}{ }^{32} \mathrm{P}\right] \mathrm{d}-\mathrm{TTP}\right)$ in a total volume of 1 $\mathrm{ml}$ of $10 \mathrm{mmol} / \mathrm{L}$ Tris $(\mathrm{pH} 7.8), 150 \mathrm{mmol} / \mathrm{L} \mathrm{NaCl}, 1 \mathrm{mmol} / \mathrm{L}$ EDTA, and $0.15 \%$ gelatin. Antisera were added to the reaction at a dilution yielding $30 \%$ to $60 \%$ binding to a labeled ligand, and incubated at $4^{\circ} \mathrm{C}$ overnight; the immune complex was then precipitated with goat anti-rabbit IgG (CalBiochem) and carrier serum obtained from nonimmunized rabbits. The immune complex was pelletted at 3500 rpm at $4^{\circ} \mathrm{C}$ for 45 minutes and then solubilized for 15 minutes on a rotator at $37^{\circ} \mathrm{C}$. Sample inhibition was extrapolated by a standard curve to determine the number of photoproducts in $10^{6}$ bases ([6-4]PPs/Mb or CPDs/Mb). For the standard, double-stranded salmon testis DNA was UVB-irradiated at increasing doses of UV radiation and heat-denatured. The percent inhibition of bound ${ }^{32} \mathrm{P}$ from sample DNA was compared with control UV-irradiated salmon testis DNA to determine the quantity of the photoproducts. Rabbit polyclonal (6-4)PPs and CPDs primary antisera were prepared at MD Anderson Cancer Center.

\section{p53 Mutation Analysis Using Allele-Specific PCR}

Briefly, epidermal or skin tumor DNA was isolated and analyzed using allele-specific PCR for CC $\rightarrow$ TT mutations at codons 154/155 in exon 5 of the P53 gene and for $C$ to T mutations at codons 270 and 275 in exon 8 of the $P 53$ gene as described previously.5,27-29 The PCR primers used included the codons 154/155: 5'-CCTCCAGCTGGGAGCCGTGCTT-3' (with mutant-specific sequences) and 5'-GAGGGCTTACCATCACCATC-3'; C to T mutations at codons 270 and 275: the forward mutant-specific sequences 5'-GGACGGGACAGCTTTGAGGTTT-3' and 5'-GTGTTTGTGCCTGCCT-3', respectively, and the reverse sequences 5'-GCCTGCGTACCTCTCTTTGC-3'. The PCR primers for exon 5 of the p53 gene were $5^{\prime}$ TCTCTTCCAGTACTCTCCTC-3' and 5'-GAGGGCTTAC- 
CATCACCATC-3'. PCR was performed using $360 \mathrm{ng}$ of genomic DNA, $2 \mu \mathrm{mol} / \mathrm{L}$ each primer, $2.5 \mu \mathrm{mol} / \mathrm{L}$ dNTPs, and $0.2 \mathrm{U}$ of TaqDNA polymerase (Promega) in a buffer containing $1 \mathrm{mmol} / \mathrm{L} \mathrm{MgCl}_{2}$ in a final volume of $25 \mu \mathrm{l}$. Following an initial denature step ( 4 minutes at $\left.94^{\circ} \mathrm{C}\right), 35$ cycles $\left(1\right.$ minute at $94^{\circ} \mathrm{C} ; 1$ minute each at $58^{\circ} \mathrm{C}$ [codon 154 to 155 mutations], $69^{\circ} \mathrm{C}$ [codon 270] or $65^{\circ} \mathrm{C}$ [codon 275]; and 1 minute at $72^{\circ} \mathrm{C}$ ) were performed using a DNA thermal cycler (BioRad). An aliquot (15 $\mu \mathrm{l})$ of the PCR product was mixed with a DNA gel loading solution (3 $\mu \mathrm{l}$ ) and electrophoresed on $8 \%$ (codons 154) or 6\% (codons 270 and 275) polyacrylamide gels at $150 \mathrm{~V}$ for 30 minutes and then visualized using SYBR Green II staining (Invitrogen, Carlsbad, CA).

\section{Gel Shift Assay}

Electrophoretic mobility shift assays of NF- $\kappa$ B DNA binding activity were performed using a kit (E3300; Promega). Reaction containing $7.5 \mu \mathrm{l}$ of $2 \times$ electrophoretic mobility shift assay buffer, $1.5 \mu \mathrm{g}$ of poly dl-dC, $10 \mu \mathrm{g}$ of protein lysates, $5 \times 10^{3} \mathrm{cpm} \mathrm{NF- \kappa B}$ probe, and up to $15 \mu \mathrm{l}$ of water, was incubated at room temperature for 30 minutes. A gel $5 \%$ nondenatured polyacrylamide gel was pre-run in $0.5 \times$ TBE for 1.5 hours at $100 \mathrm{~V}$, and then the reactions were subjected into the gel. The gel was dried and exposed to film. ${ }^{30}$

\section{$R T-P C R$}

Total RNA was isolated from the epidermis or keratinocytes using TRI Reagent (Molecular Research Center). ${ }^{23}$ cDNA was synthesized by a RETROscript kit (Ambion, Inc). PCR primers used included tumor necrosis factor (TNF) $\alpha$ (5'-GATCTCAAAGACAACCAACATGTG-3' and 5'CTCCAGCTGGAAGACTCCTCCCAG-3'), interleukin (IL)-6 (5'-CATAGCTACCTGGAGTACATGA-3' and 5'-CATTCATATTGTCAGTTCTTCG-3'), IL-1 (5'-CCAGGATGAGGACATGAGCACC-3' and 5'-TTCTCTGCAGACTCAAACTCCAC-3'), and GAPDH. ${ }^{17}$

\section{Antibodies}

Antibodies used in this study included those against IKK $\alpha$ (IMG 136; Imgenex), p-ERK (9109; Cell Signaling Technology), ERK1 (SC-93; Santa Cruz Biotechnology), ERK2 (SC-1647; Santa Cruz), Akt (9272; Cell Signaling Technology), p-Akt (9271S; Cell Signaling Technology), MCP-1/CCL2 (554590; BD, NJ), and $\beta$-Actin (A-5441; Sigma).

\section{Keratinocyte Culture}

Mouse primary keratinocytes were isolated and cultured as described previously. ${ }^{23}$ Briefly, skin specimens isolated from newborn mice were treated with $0.25 \%$ trypsin (15050-065, Invitrogen) for 8 to 10 hours at $4^{\circ} \mathrm{C}$; the epidermis was separated from the dermis. Isolated keratinocytes were plated on $60-\mathrm{cm}$ cell dishes containing keratinocyte serum-free medium (10785, GIBCO, Rockville, MD). Five days later, cultured keratinocytes were irradiated with $100 \mathrm{~mJ} / \mathrm{cm}^{2}$. Cells and supernatants were collected at 24 hours after irradiation.

\section{ELISA Assay}

MCP-1 levels in the supernatant of primary cultured keratinoytes were measured by MCP-1 ELISA kit (MJE00, R\&D Systems, Minneapolis, MN) in clinical services laboratories, Basic Research Program, SAIC Frederick.

\section{Chemotaxis Assay}

Chemotaxis of mouse macrophages was measured with 48-well microchambers and polycarbonate filters (5- $\mu \mathrm{m}$ pore size; NeuroProbe, Cabin John, MD) as previously described. ${ }^{31}$ Briefly, a $27-\mu$ l aliquot of testing materials was placed in the wells of the lower compartment of the chamber, and $50 \mu$ l of mouse peritoneal macrophages (at $2 \times 10^{6} / \mathrm{ml}$ ) were placed in the wells of the upper compartment. Two compartments of the chemotaxis chamber were separated by an 8- $\mu \mathrm{m}$ pore-sized polycarbonate filter (GE Osmonics Labstore, Minnetonka, $\mathrm{MN})$. After incubation at $37^{\circ} \mathrm{C}$ for 90 minutes, the filters were removed and stained, and cells that migrated across the filters were counted under light microscopy. The mean number ( \pm SE) of migrated cells in three high-powered fields ( $\times 400$ magnification) in triplicate samples was obtained, and the results were expressed as chemotaxis index $(\mathrm{Cl})$ representing the fold increase in cell migration in response to stimulants over medium control. Student $t$ test was used to examine the statistical significance in the differences of chemotaxis shown by various groups. Recombinant mouse MCP-1 (554590; $\mathrm{BD})$ was used for control of MCP-1.

\section{Results}

\section{Reduction in IKK $\alpha$ Expression Shortens Tumor Latency and Enhances Tumor Numbers and Weights After Chronic UVB Irradiation in Mice}

To determine the effect of reduced IKK $\alpha$ expression on UVB skin carcinogenesis, we treated $l k k \alpha^{+/+}$and $l k k \alpha^{+/-}$ mice with UVB three times a week for 28 weeks. The $1 k k \alpha^{+/-}$mice appeared to be normal although $l k k \alpha^{-1-}$ mice die soon after birth because of severe defects in the skin development. ${ }^{15,16}$ We observed tumors on the dorsal skin of $I k k^{+/-}$mice at week 11 after UVB irradiation, and almost all of these $1 k k^{+/-}$mice $(95 \%)$ rapidly developed tumors over the next 5 weeks (Figure 1A). We observed skin tumors in $1 \mathrm{kk}^{+/+}$mice at week 14 after UVB irradiation, and all of these $l k k^{+/+}$mice had tumors by 23 weeks. These results showed that reduction of IKK $\alpha$ expression decreased tumor latency $(P<0.001$, COX proportional hazards model; Figure 1A). Tumor multiplicity analysis showed that $l k_{k \alpha^{+/-}}$mice developed significantly more tumors than did $I k k \alpha^{+/+}$mice $(P<$ 
A
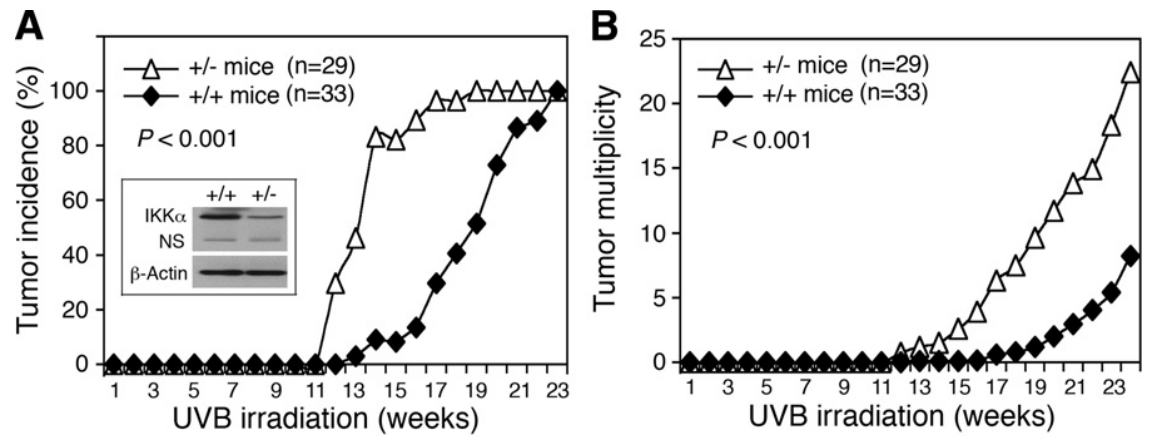

UVB irradiation (weeks)
C

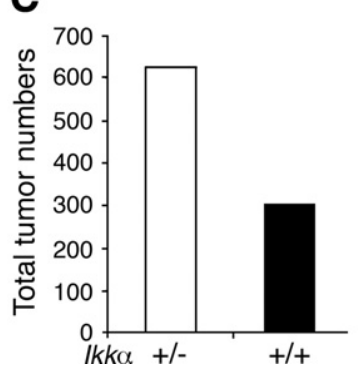

D

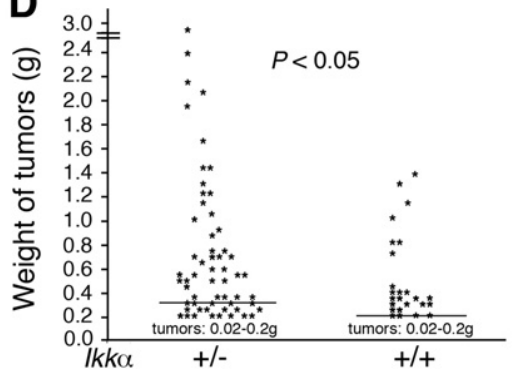

Figure 1. Reduction of IKK $\alpha$ expression promotes UVB skin carcinogenesis in mice. A: Skin tumor incidence in $I k k \alpha^{+/+}(+/+)$and $I k k \alpha^{+/ /}$ $(+/-)$ mice $(P<0.001$, COX proportional hazards model). IKK $\alpha$ protein levels were detected by Western blotting. $\beta$-Actin, loading control. NS indicates nonspecific band. B: Tumor multiplicity in $I k k \alpha^{+/+}$and $I k k \alpha^{+/-}$mice $(P<0.001$ Poisson regression analysis). C: Tumor numbers in $33 \mathrm{Ikk \alpha ^{+/+ }}$ and $29 \mathrm{Ikk \alpha ^{+/- }}$ mice at week 28 D: Weight comparison of tumors found in 33 $I k k \alpha^{+/+}$and $29 I k k \alpha^{+/-}$mice $(P<0.05, t$ test $)$ Lines indicate means; g, Gram (tumor weights).
0.001, Poisson regression analysis; Figure 1B). At week 28 of the experiment, the $l k_{k a}{ }^{+/-}$mice had twice as many tumors as the $/ k k \alpha^{+/+}$mice (Figure $1 \mathrm{C}$ ). Histological examination showed that, regardless of genotypes of the Ikk $\alpha$ gene in mice, most skin tumors were SCCs (supplemental Figure S1, see http://ajp.amjpathol.org) and some of small tumors remained papillomas. A comparison of tumor weights found more large tumors in $1 k k \alpha^{+/-}$mice than in $l k k \alpha^{+/+}$mice $(P<0.005$, $t$ test; Figure 1D). Collectively, these results showed that $I k k \alpha^{+/-}$mice were more prone to chronic UVB-induced skin carcinogenesis than were $l k k \alpha^{+/+}$mice; in particular, the tumor latency was significantly shorter in $l k k \alpha^{+/-}$than in $I k k \alpha^{+/+}$mice.

\section{Early Genetic Alteration: More UVB-Induced Signature p53 Mutations in $1 k k^{+/-}$Skin than in $1 k k \alpha^{+/+}$Skin}

UVB-induced p53 mutations have been shown to be an important early genetic event for carcinogenesis. ${ }^{27}$ UVBsignature CC-TT and C-T mutations in p53 codons 154/ 155,270 , and 275 were detected in the epidermis as early as after 1 week of chronic UV irradiation. ${ }^{5}$ To identify the early events that may contribute to the tumor development promoted by reduction of IKK $\alpha$ expression, we examined UVB-induced $p 53^{\text {V154AVR155C }}, p 53^{R 270 C}$, and $p 53^{R 275 C}$ signature mutations in the skin of mice irradiated for 2 weeks using PCR with mutation-specific primers. $^{8,29}$ The result showed that these $p 53$ mutations occurred more frequently in $I k k \alpha^{+/-}$than in $I k k \alpha^{+/+}$skin specimens (Figure 2A). However, most of the skin tumors, regardless of the genotype, were positive for these p53 mutations (Figure 2B). Because $/ k_{k} \alpha^{+/-}$had twice as many tumors as $1 k k \alpha^{+/+}$mice and most of the tumors in $I k k \alpha^{+/+}$and $l k k \alpha^{+/-}$mice were positive for p53 muta- tions, the enhanced early p53 damage in the skin of $I k k^{+/-}$mice may contribute to the development of UVBinduced skin tumors.

Sites of neighboring pyrimidine bases in DNA strands are preferentially damaged by UVB radiation, forming primarily CPDs and (6-4)PPs. ${ }^{32}$ These DNA lesions give rise to unique mutations in the genome. The predominant DNA repair pathway for pyrimidine dimers in mammals is the nucleotide excision repair pathway. ${ }^{33}$ To determine whether DNA repair defects increase the number of p53 mutations in $1 k^{k} \alpha^{+/-}$skin cells, we examined the levels of CPDs and (6-4)PPs in the epidermis of mice at different time points after UVB irradiation using a specific radioimmunoassay. ${ }^{26,34}$ We found similar levels of CPDs and (6-4)PPs in the epidermal DNA of $/ k a^{+/+}$and $/ k k \alpha^{+/-}$ mice immediately after UVB irradiation but no detectable CPDs or (6-4)PPs in untreated murine epidermal specimens (supplemental Figure S2, A and B, see http://ajp. amjpathol.org). At 24 hours after irradiation, most of the (6-4)PPs were repaired, and the level of (6-4)PPs dropped to a basal level comparable with that in untreated skin specimens (supplemental Figure S2C, see http://ajp.amjpathol.org); this repair in the epidermal cells in $I k k \alpha^{+/-}$and $l k k \alpha^{+/+}$mice was not statistically significant. Also, most of the CPDs photoproducts were repaired in the genome at 24 hours after irradiation. The CPDs repair kinetics curves for the epidermis of $l k k \alpha^{+/-}$ and $I k k \alpha^{+/+}$mice were identical (supplemental Figure S2D, see http://ajp.amjpathol.org). These results suggest that the DNA repair pathways may not be major players for increased numbers of early p53 mutations in the skin of UVB-treated $l k k^{+1-}$ mice within 24 hours. Because cellular DNA will be duplicated after 24 hours after irradiation, the method may only be used to monitor DNA repair within a short period of time. 
A

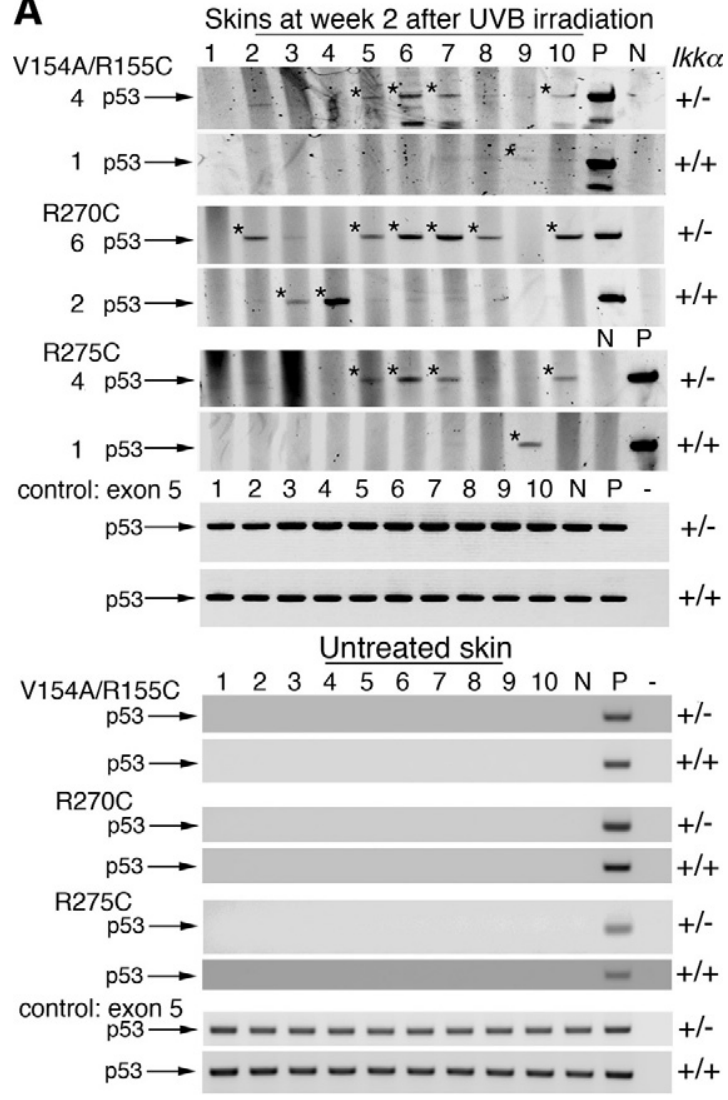

B UVB-induced skin tumors

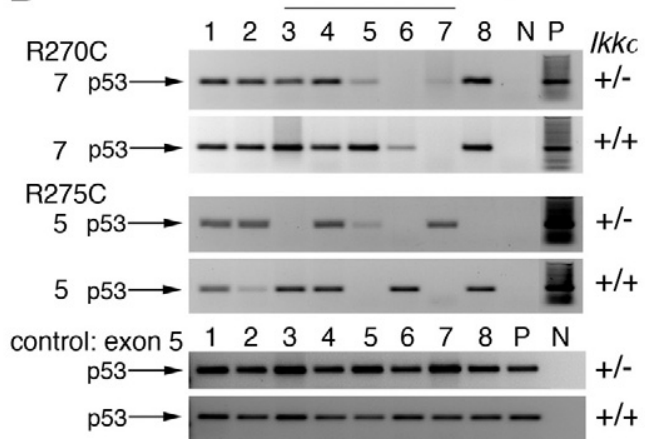

Figure 2. Reduction of IKK $\alpha$ expression enhances early UVB-induced $p 53$ mutations in mouse skin detected by allele-specific PCR. A: Detection of $p 53$ mutations (V154A/R155C, R270C, R275C) $)^{29}$ in skins of $I k k \alpha^{+/+}(+/+)$and $I k k \alpha^{+/-}(+/-)$mice at week 2 after UVB irradiation and in skins of untreated $I k k \alpha^{+/+}(+/+)$and $I k k \alpha^{+/-}(+/-)$mice. $\mathrm{V}$ indicates valine; A, alanine; $\mathrm{R}$, arginine; $\mathrm{C}$, cysteine. The numbers on the left represent $p 53$ mutationpositive skins. $+/+, I k k \alpha^{+/+}$skin; $+/-, I k k \alpha^{+/-}$skin; " $p 53$ PCR bands with mutations; exon 5 , exon 5 of the $p 53$ gene as PCR controls; $\mathrm{P}$, positive control (UVB-induced skin tumors); $\mathrm{N}$, negative control for $p 53$ mutations; - , no DNA in PCR. B: Detection of p53 mutations (R270C; R275C) in skin tumors developed in $I k k \alpha^{+/+}$and $I k k \alpha^{+/-}$mice at the end point of the experiment.

\section{Reduction in UVB-Induced Apoptotic/Sunburn Keratinocytes in Ikk ${ }^{+/-}$Skin Compared with Those in $1 k \alpha^{+/+}$Skin}

Previous studies showed that reduced UVB-induced apoptosis was able to accumulate p53 mutation-positive cells during UVB carcinogenesis, ${ }^{8,13}$ thus we examined UVB-induced cell death in the skin of $l k k \alpha^{+/+}$and $l k k \alpha^{+/-}$
A

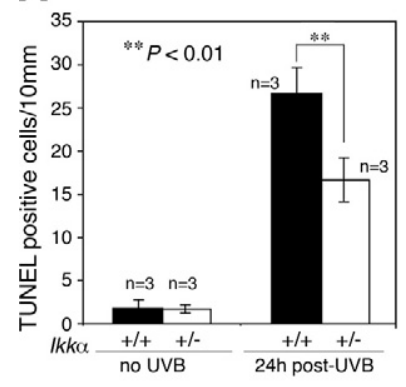

B
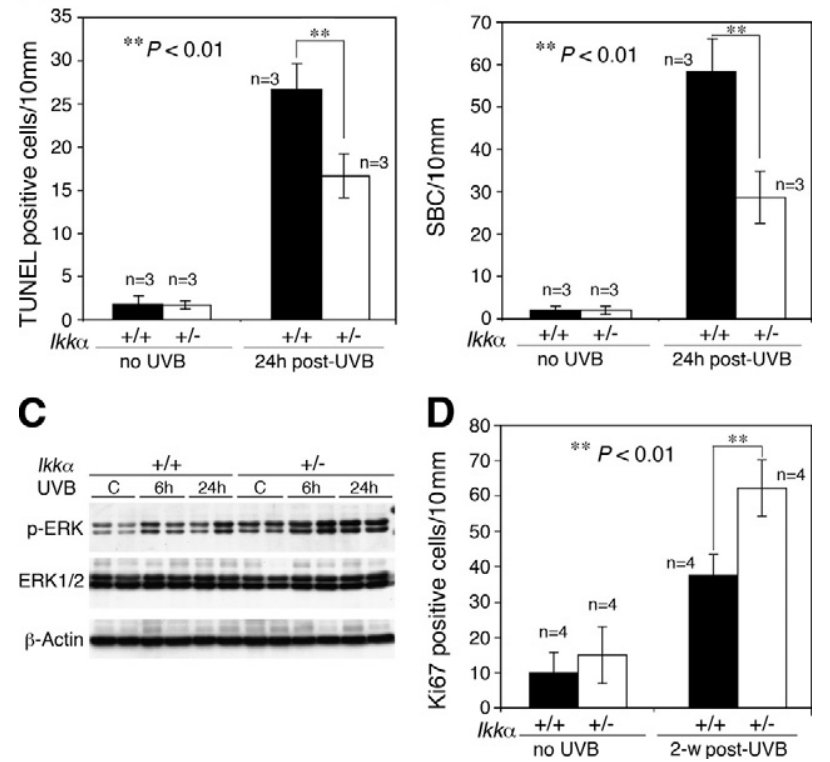

Figure 3. Reduction of IKK $\alpha$ expression suppresses UVB-induced apoptosis in mouse skin and promotes cell proliferation. $\mathbf{A}$ and $\mathbf{B}$ : Paraffin-embedded skin sections obtained from $I k k \alpha^{+/+}(+/+)$and $I k k \alpha^{+/-}(+/-)$mice using a TUNEL assay kit and the number of TUNEL-positive cells determined under a microscope. Groups of mice $(n=3)$ used. The SBCs in the epidermis of hematoxylin and eosin-stained skin sections were counted. 24 hours postUVB, skin sections prepared from mice at 24 hours after UVB irradiation at $100 \mathrm{~mJ} / \mathrm{cm}^{2} .{ }^{* *} P<0.01, t$ test. C: Levels of p-ERK and ERK in skin specimens obtained from UVB-irradiated mice detected using Western blotting. $\beta$-Actin, protein loading controls; C, untreated sample; 6 hours and 24 hours, samples prepared from mice at 6 hours and 24 hours post-UVB irradiation (100 $\mathrm{mJ} / \mathrm{cm}^{2}$ ). D: Comparison of Ki-67-positive cells immunohistochemically stained in the interfollicle epidermis of mice. Groups of mice $(n=4)$ used. 2 -w post-UVB, skin sections prepared from mice at week 2 after treatment with UVB at $100 \mathrm{~mJ} / \mathrm{cm}^{2}$. ${ }^{* *} P<0.01, t$ test.

mice at 24 hours after irradiation. The number of apoptotic cells as measured using TUNEL staining was dramatically higher in $/ k k \alpha^{+/+}$than in $l k k \alpha^{+/-}$epidermal specimens after irradiation ( $P<0.01, t$ test), but there was no difference in unirradaited $l k k \alpha^{+/+}$and $l k k \alpha^{+/-}$mice (Figure 3A). We counted the SBCs in the epidermis as another indicator of UVB-induced cell death, the result of which was similar to that of TUNEL staining ( $P<0.01$, $t$ test; Figure 3B). These data suggest that reduction of $\mathrm{IKK} \alpha$ expression suppresses UVB-mediated apoptosis in skin cells, which may accumulate $p 53$ mutation-cells in the skin and promote UVB carcinogenesis.

\section{Reduction in IKK $\alpha$ Expression Enhances Mitogenic and Mitotic Activities in the Skin of Mice after UVB Irradiation}

Furthermore, we examined cell proliferating related pathways, which have been suggested to antagonize apoptosis. ${ }^{35}$ We found higher UVB-induced ERK activity and more Ki-67-positive proliferating cells in $/ k k^{+/-}$skin than in $l k k \alpha^{+/+}$skin specimens $(P<0.01$; $t$ test; Figure 3, C and $D)$. There were no significant differences in the pattern of positive Ki-67 cells distributed in the basal epidermal cells of $I k k \alpha^{+/+}$and $I k k \alpha^{+/-}$mice. To further determine cell mitotic state, we examined a mitotic cell marker, 


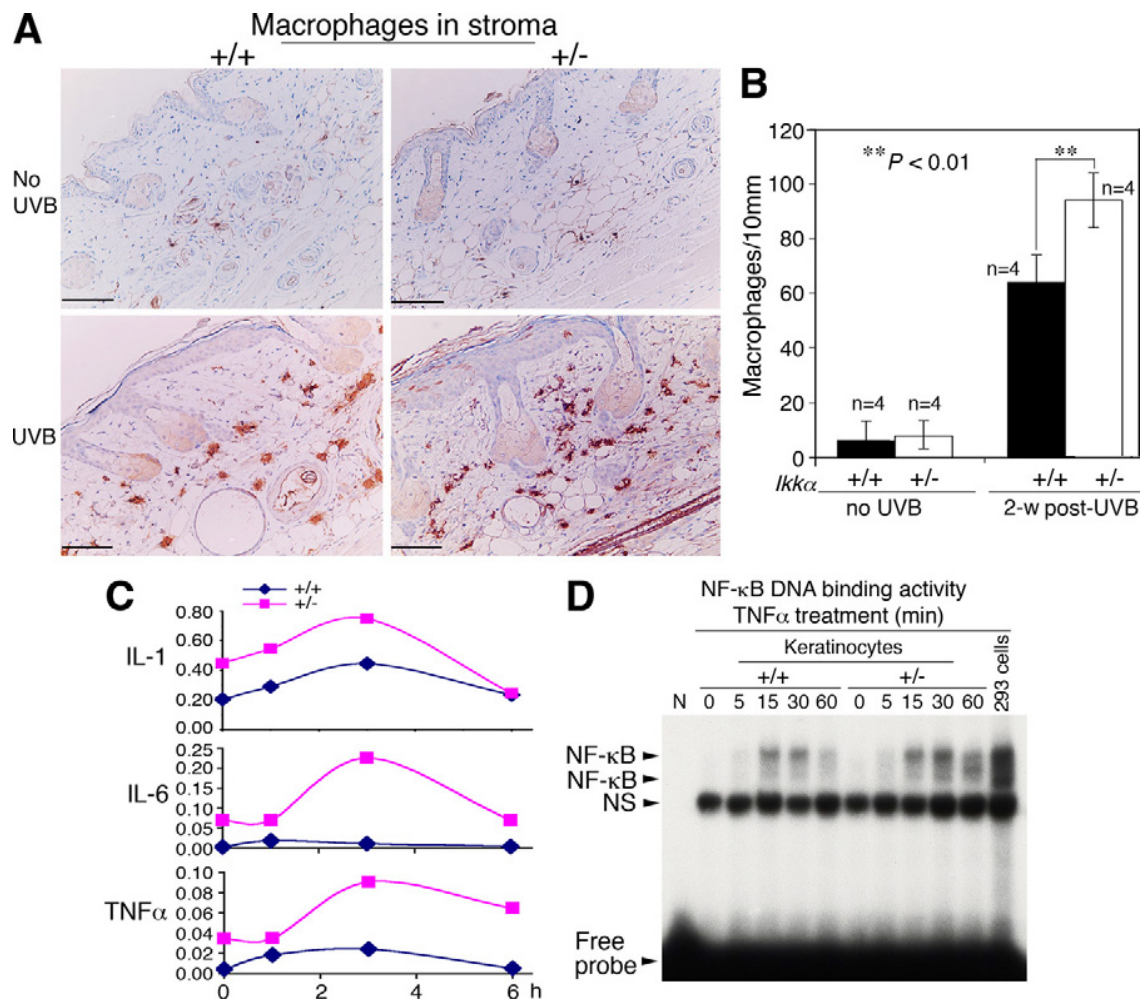

Figure 4. Reduction of IKK $\alpha$ expression elevates inflammation in the skin. A: Detection of macrophages in $I k k \alpha^{+/+}(+/+)$and $I k k \alpha^{+/-}$ $(+/-)$ paraffin-embedded skin sections, immunohistochemically stained with a macrophage marker. Brown color, macrophages; blue color, nuclear countingstaining with hemetoxylin; UVB, UVB irradiation for 2 weeks. B: Comparison of numbers of macrophages in the skin stroma of UVB-irradiated $I k k \alpha^{+/+}(+/+)$and $I k k \alpha^{+/-}(+/-)$mice shown in A. Groups of mice $(n=4)$ used. 2 -w post-UVB, skin prepared from mice at week 2 after UVB irradiation with $100 \mathrm{~mJ} / \mathrm{cm}^{2} .{ }^{* *} P<0.01, t$ test. Scale bars $=30$ $\mu \mathrm{m}$. C: Relative levels of TNF $\alpha$, IL-6, and IL-1 mRNA in UVB-irradiated $I k k \alpha^{+/+}(+/+)$and $I k k \alpha^{+/-}(+/-)$primary cultured keratinocytes detected using RT-PCR. Levels of GAPDH mRNA were used to normalize the expression levels of these cytokines. Each point $(n=3)$ used. 2, 4, 6 hours, primary cultured keratinocytes were collected at 2, 4, and 6 hours after irradiation (100 $\mathrm{mJ} / \mathrm{cm}^{2}$ ). D: NF- $\kappa$ B DNA-binding activity in primary cultured keratinocytes treated with TNFo $(10 \mathrm{ng} / \mathrm{ml})$ from 0 to 60 minutes. 293 cells treated with TNF $\alpha$ for 30 minutes were used as a positive control. NS indicates nonspecific band.

phosphorylated histone $\mathrm{H} 3$, in the epidermis of UVBirradiated $l k k \alpha^{+/+}$and $l k k \alpha^{+/-}$mice by using immunohistochemical staining and found that there were more phosphorylated histone H3-positive cells in UVB-irradiated $I k k^{+/-}$than in UVB-irradiated $I k k^{+/+}$epidermis $(P<0.05$, $t$ test; supplemental Figure S3, see $h t t p: / /$ ajp.amjpathol.org). Collectively, the results suggest that reduction of IKK $\alpha$ expression promotes UVB-induced cell proliferation.

\section{Reduction in IKK $\alpha$ Expression Enhances Inflammation and Macrophage Recruitment in the Skin and Elevates Expression of Cytokines and MCP-1/CCL2 in Keratinocytes, Which Enhances Macrophage Migration}

UVB irradiation-mediated chronic inflammation promotes tumor development, in which infiltrating macrophages are important players. ${ }^{12}$ Thus, we examined macrophages in the skin stroma by using immunohistochemical staining with a macrophage maker and found that there were more macrophages in the skin stroma of $I k k \alpha^{+/-}$ mice than in the skin stroma of $l k k \alpha^{+/+}$mice at week 2 after irradiation ( $P<0.01$, $t$ test; Figure $4, A$ and $B$ ). To determine whether reduced IKK $\alpha$ expression in keratinocytes contributed to the increased inflammation, we isolated keratinocytes from $I k k \alpha^{+/-}$and $l k k \alpha^{+/+}$mice, cultured these cells, and examined expression levels of $\mathrm{TNF} \alpha, \mathrm{IL}-6$, and IL-1 after treatment with UVB. The levels of these cytokines were higher in $l k k \alpha^{+/-}$than in $l k k \alpha^{+/+}$ keratinocytes (Figure 4C). Because elevated TNF $\alpha$ expression induces apoptosis in cells in which NF- $\kappa \mathrm{B}$ ac- tivity is decreased. ${ }^{36}$ we then examined NF- $\kappa$ B DNA binding activity in UVB-treated $I k k^{+/-}$and $I k k \alpha^{+/+}$primary cultured keratinocytes and found that this activity was not reduced in $I k k^{+/-}$compared with that in $I k k^{+/+}$ keratinocytes after TNF $\alpha$ treatment (Figure 4D). This result is consistent with previous studies ${ }^{30,37}$ in which it is thought that, in the absence of $\mathrm{IKK} \alpha, \mathrm{IKK} \beta$ replaced IKK $\alpha$ in the IKK complex. Because IKK $\beta$ is a stronger kinase for $I_{\kappa} \mathrm{Bs}$ than is $\mid \mathrm{KK} \alpha{ }^{38,39} \mathrm{IKK} \alpha$ loss may preserve or promote IKK/NF- $\kappa \mathrm{B}$ activity. Together, these results suggest that elevated expression of cytokines in keratinocytes expressing reduced $\mathrm{IKK} \alpha$ levels may contribute to increased inflammation in the skin.

MCP- 1 is a target of NF- $\kappa \mathrm{B}$ and $\mathrm{TNF} \alpha$, and it promotes migration of macrophages. ${ }^{40,41}$ To determine whether reduction in $\mathrm{IKK} \alpha$ expression upregulates expression of MCP-1 in keratinocytes, we collected the supernatant of primary cultured $I k k \alpha^{+/-}$and $I k k \alpha^{+/+}$keratinocytes after irradiation and found that the level of MCP-1 was significantly higher in the supernatant of $I \mathrm{kk}^{+/-}$keratinocytes than in the supernatant of $l k k \alpha^{+/+}$keratinocytes, examined by using ELISA assay ( $P<0.01, t$ test; Figure 5A). To determine the effect of the supernatants on macrophage migration, we first examined the effect of different concentrations of the recombinant $\mathrm{MCP}-1$ on the migration of macrophages isolated from wild-type mice and found that macrophage migration was MCP-1 dose-dependent $(P<0.01$, $t$ test; Figure 5B). By using this assay, we found that the supernatant of UVB-irradiated $I k k^{+/-}$ keratinocytes had a significantly higher activity in inducing macrophage migration than did the supernatant of UVB-irradiated $\mathrm{lk} \mathrm{k}^{+/+}$keratinocytes $(P<0.01$, $t$ test; Figure $5 \mathrm{C})$. The antibody against MCP-1 was able to 
A

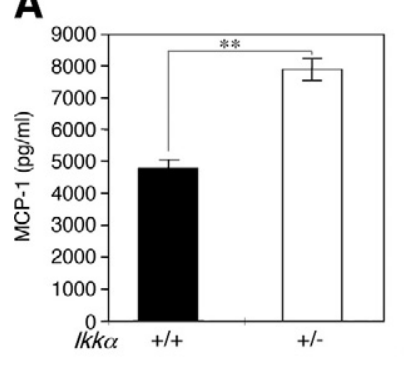

B
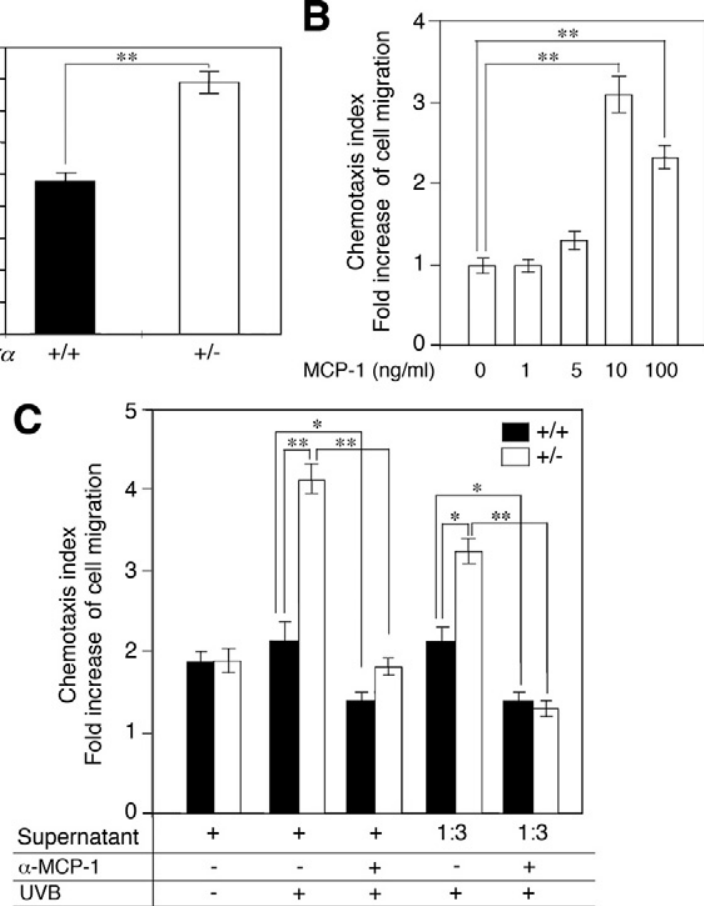

Figure 5. Reduction of IKK $\alpha$ in keratinocytes promotes expression of MCP-1 and macrophage migration. A: Comparison of MCP-1 expression in UVBirradiated primary cultured $I k k \alpha^{+/+}(+/+)$and $I k k \alpha^{+/-}(+/-)$keratinocytes at 24 hours after irradiation by using ELISA assay. ${ }^{* *} P<0.01, t$ test. B: Activity of recombinant MCP-1 in inducing macrophage migration. ${ }^{* *} P<0.01, t$ test. C: Comparison of activities of the supernatant of primary cultured $I k k \alpha^{+/+}$ $(+/+)$ and $I k k \alpha^{+/-}(+/-)$keratinocytes. UVB, collecting cells at 24 hours after UVB treatment at $100 \mathrm{~mJ} / \mathrm{cm}^{2} ; \alpha$-MCP-1, antibody against MCP-1; $1: 3$, $1 / 3$ dilution. ${ }^{*} P<0.05, t$ test; ${ }^{* *} P<0.01, t$ test.

abolish the activity of macrophage migration in the supernatant of keratinocytes $(P<0.01, t$ test; Figure $5 \mathrm{C})$. Together, the results suggest that reduction of $\mathrm{IKK} \alpha$ expression in keratinocytes may promote the recruitment of macrophages and inflammation by upregulating expression of cytokines and $\mathrm{MCP}-1$ during UVB skin carcinogenesis.

\section{Discussion}

In the present study, $I k k \alpha^{+/-}$mice were found to have twice as many skin tumors than $l k k \alpha^{+/+}$mice did after chronic UVB exposure. Also, the tumors occurred significantly earlier in $l k k \alpha^{+/-}$mice than in $l k k \alpha^{+/+}$mice. Thus, the IKK $\alpha$ level had an important impact in the early events during UVB skin carcinogenesis. A better understanding of how IKK $\alpha$ affects these early events may provide new insight into prevention of skin cancer.

UVB-induced signature p53 mutations can be detected at one week after UVB irradiation in mice. ${ }^{5}$ These early genetic events have been demonstrated to be important for UVB carcinogenesis because these mutations can interrupt the tumor suppressor function of p53. ${ }^{6}$ We detected more early UVB-induced signature p53 mutations in $l k k \alpha^{+/-}$than in $l k k \alpha^{+/+}$skin specimens (Figure 2A). Although the tumor latency was significantly shorter in $I k k \alpha^{+/-}$mice than in $l k k \alpha^{+/+}$mice, all skin tumors derived from $l k k \alpha^{+/+}$and $l k k \alpha^{+/-}$mice contained $p 53$ mutations. It appears that these early genetic events were significant for promoting UVB carcinogenesis. Thus, reduction in $\mathrm{I} K \mathrm{~K} \alpha$ expression may have an impact on human skin cells carrying p53 mutations after chronic UVB exposure. Although we did not detect increased photoproducts (6-4)PPs and CPDs in $l k k \alpha^{+/-}$epidermis compared with those in $l k k \alpha^{+/+}$epidermis (supplemental Figure S2, A-D, see http://ajp.amjpathol.org), the method used in this study was only able to monitor those photoproducts within 24 hours after UVB irradiation because cellular DNA duplication occurred. We previously reported that loss of $1 \mathrm{KK} \alpha$ reduces the $\mathrm{G}_{2} / \mathrm{M}$ cell cycle checkpoint in response to DNA damage, which can also amplify cells carrying DNA damage because cells deficient in the $G_{2} / M$ cell cycle checkpoint do not have enough time to repair DNA damage. ${ }^{42}$ Moreover, the UVB-mediated p53 mutations may impair the function of p53 in induction of apoptosis in response to UVB irradiation, thereby allowing the cells carrying p53 mutations to survive in mice.

We previously reported that $\mathrm{IKK} \alpha$ deletion in keratinocytes provided a growth advantage by elevating an autocrine loop of EGFR, Ras, ERK, EGFR ligands (growth factors), and these ligands' activators. ${ }^{22}$ Increased mitotic activity is known to be able to attenuate apoptotic activity and promote cell growth. ${ }^{35}$ In this study, we also detected that reduction of IKK $\alpha$ expression elevated ERK activity and promoted cell proliferation in the epidermis of mice after UVB irradiation. Furthermore, at the early stage of UVB skin carcinogenesis, we not only observed more signature p53 mutations but also detected more skin tumors in $I k k \alpha^{+/-}$mice than in $l k k \alpha^{+/+}$mice. Collectively, these results suggested that the growth advantage provided by reduction in $\mathrm{IKK} \alpha$ expression might promote expansion of cells containing p53 mutations.

UVB-induced chronic inflammation is important for skin carcinogenesis. $^{7,11}$ In the current study, we observed more UVB-induced infiltrating macrophages in $1 k k \alpha^{+/-}$ than in $l k k \alpha^{+/+}$skin stroma (Figure 5A). I $k k^{+/-}$keratinocytes were found to express more TNF $\alpha$, IL-6, and IL-1 than $I k k \alpha^{+/+}$keratinocytes did after UVB irradiation. The level of MCP-1, a monocyte chemoattractant protein and a target of $\mathrm{TNF} \alpha,{ }^{40,41}$ was higher in the supernatant of $I k k \alpha^{+/-}$than in the supernatant of $l k k \alpha^{+/+}$keratinocytes after UVB irradiation. The supernatant of $l k k \alpha^{+/-}$keratinocytes showed elevated MCP-1-dependent activities in inducing macrophage migration compared with those did the supernatant of $l \mathrm{kk} \alpha^{+/+}$keratinocytes (Figure 5C). It is thought that the chronic infiltrating macrophages are able to create a microenvironment that is prone to cell proliferation and DNA damage. ${ }^{12}$ Together, the defects identified in $l k k \alpha^{+/-}$mice described above may be important for promoting inflammation and accelerating UVB carcinogenesis.

Chemical carcinogens 7,12-dimethylbenz[a]anthracene (DMBA) and 12-O-tetradecanoylphorbol-13-acetate (TPA) induce skin papillomas and carcinomas in mice by initiating Ras mutations. ${ }^{43}$ P53 mutations are involved in UVB-induced skin carcinogenesis. ${ }^{11}$ Although $1 \mathrm{kk}^{+/-}$ mice developed many more skin tumors than did $I k k \alpha^{+/+}$ mice induced by chemical carcinogens, ${ }^{23}$ we did not 
detect increased Ras mutations in the skin of $l \mathrm{kk}^{+/-}$ mice compared with those in the skin of $l k k \alpha^{+/+}$mice (our unpublished data) and did not obverse reduced apoptosis in $l k k \alpha^{+/-}$epidermis compared with that in the $l k k \alpha^{+/+}$ epidermis at the early stage of the DMBA and TPA induced skin carcinogenesis. ${ }^{23}$ In this study, we detected increased UVB-induced signature p53 mutations in the $1 k k \alpha^{+/-}$compared with those in the $I k k \alpha^{+/+}$skin at week 2 after irradiation and shortened tumor latency in $1 k^{k} \alpha^{+/-}$ mice. Taken together, reduction of IKK $\alpha$ expression can cooperate with the different carcinogens to promote skin tumor development in vivo.

In many human SCC cells, NF- $\kappa$ B activity was elevated. ${ }^{44}$ Studies have shown that NF- $\kappa$ B activity is able to protect cells from TNF receptor pathway-induced cell death, ${ }^{36}$ which may be important for cell survival during tumor development. ${ }^{45} \mathrm{IKK} \alpha$ and IKK $\beta$ are highly conserved protein kinases, however, $\mathbb{I K K} \beta$ is a stronger kinase for $I_{\kappa} B s$ than IKK $\alpha .{ }^{39}$ Previously, we showed higher $\mathrm{IKK} / \mathrm{NF}-\kappa \mathrm{B}$ DNA binding activity in $1 \mathrm{kK}^{-\alpha^{--}}$than in wildtype keratinocytes after treatment with TNF $\alpha$ and IL-1. ${ }^{30} \mathrm{It}$ was thought that IKK $\beta$ homodimers may replace IKK $\alpha$ | IKK $\beta$ heterodimers in the absence of IKK $\alpha$ in keratinocytes. Our result in the present study found elevated expression levels of TNF $\alpha$, IL-1, and IL-6 in Ikk ${ }^{+/-}$compared with those in wild-type keratinocytes after UVB treatment and higher NF- $\kappa \mathrm{B}$ DNA binding activity in $1 k k \alpha^{+/-}$than in wild-type keratinocyte after treatment with TNF $\alpha$. Thus, the elevated NF- $\kappa \mathrm{B}$ activity in $l k k^{+/-}$keratinocytes may not only elevate cytokine expression but also promote cell survival and cell migration during UVB carcinogenesis.

We noticed the discrepancy for the proposed IKK $\alpha$ function in UVB carcinogenesis between our results and other results. ${ }^{46-48}$ Those studies showed that chemoprevention agents including grape seed proanthocyanidins, epigallocatechin-3-gallate, and resveratrol repressed UVB-induced nuclear NF- $\kappa \mathrm{B}$ activity and cytosol IKK $\alpha$ levels in the mouse skin or keratinocytes, ${ }^{46-48}$ suggesting that elevated IKK $\alpha$ levels may contribute to activation of $N F-\kappa B$ after treatment with UVB. However, in the current study, we showed that NF- $\mathrm{B}$ activity was higher in $I k k \alpha^{+/-}$than in wild-type keratinocytes and that reduction in IKK $\alpha$ expression promoted UVB-induced skin carcinogenesis. Previously, we and others showed that most of $\mathrm{IKK} \alpha$ proteins were localized in the nucleus of keratinocytes in adult mice, and that the nuclear IKK $\alpha$ inhibited transcription of HB-EGF, EGF, amphiregulin, and EGFR ligands independently of its kinase activity. Thus, one explanation for this discrepancy is the localization of IKK $\alpha$ in cells. The cytosol IKK $\alpha$ may function as a subunit of the IKK complex that can activate NF- $\mathrm{BB}$ in cell cytoplasm and the nuclear $I \mathrm{KK} \alpha$ inhibits transcription of growth factors via a different pathway. Taken together, these results suggest that the actual content is important for understanding IKK $\alpha$ function in vivo.

In addition, many studies reported that IKK $\alpha$ crosstalks with p63, transforming growth factor $\beta$, and Smad. ${ }^{20,21,49}$ These genes are important for maintaining skin homeostasis and skin tumor development. Thus, the multi- ple pathways may also be accounted for the function of $\mathrm{IKK} \alpha$ in preventing UVB skin carcinogenesis.

Overall, our findings in the present study show that reduction of IKK $\alpha$ expression promotes the accumulation of p53 mutations, chronic inflammation, and cell growth and reduces apoptosis, which may be crucial for accelerating UVB skin carcinogenesis.

\section{Acknowledgments}

We thank Sean C. Hensley for analyzing the $1 k k \alpha$ mutations, Nancy W. Abbey for performing immunohistochemical and histological examinations, Kevin Lin for conducting the statistical analyses, and Honnavara N. Ananthaswamy for providing positive DNA controls in analysis of UVBinduced p53 mutations.

\section{References}

1. Ziegler A, Jonason AS, Leffell DJ, Simon JA, Sharma HW, Kimmelman J, Remington L, Jacks T, Brash DE: Sunburn and p53 in the onset of skin cancer. Nature 1994, 372:773-776

2. Jonason AS, Kunala S, Price GJ, Restifo RJ, Spinelli HM, Persing JA Leffell DJ, Tarone RE, Brash DE: Frequent clones of p53-mutated keratinocytes in normal human skin. Proc Natl Acad Sci USA 1996, 93:14025-14029

3. Berg RJ, van Kranen HJ, Rebel HG, de Vries A, van Vloten WA, Van Kreijl CF, van der Leun JC, de Gruijl FR: Early p53 alterations in mouse skin carcinogenesis by UVB radiation: immunohistochemical detection of mutant p53 protein in clusters of preneoplastic epidermal cells. Proc Natl Acad Sci USA 1996, 93:274-278

4. Rebel H, Mosnier LO, Berg RJ, Westerman-de Vries A, van Steeg H, van Kranen HJ, de Gruijl FR: Early p53-positive foci as indicators of tumor risk in ultraviolet-exposed hairless mice: kinetics of induction, effects of DNA repair deficiency, and p53 heterozygosity. Cancer Res 2001, 61:977-983

5. Ouhtit A, Gorny A, Muller HK, Hill LL, Owen-Schaub L, Ananthaswamy $\mathrm{HN}$ : Loss of Fas-ligand expression in mouse keratinocytes during UV carcinogenesis. Am J Pathol 2000, 157:1975-1981

6. Ananthaswamy HN, Ullrich SE, Mascotto RE, Fourtanier A, Loughlin SM, Khaskina P, Bucana CD, Kripke ML: Inhibition of solar simulatorinduced p53 mutations and protection against skin cancer development in mice by sunscreens. J Invest Dermatol 1999, 112:763-768

7. de Gruijl FR, Rebel H: Early events in UV carcinogenesis-DNA damage, target cells and mutant p53 foci. Photochem Photobiol 2008, 84:382-387

8. Hill LL, Ouhtit A, Loughlin SM, Kripke ML, Ananthaswamy HN, OwenSchaub LB: Fas ligand: a sensor for DNA damage critical in skin cancer etiology. Science 1999, 285:898-900

9. Zhang W, Hanks AN, Boucher K, Florell SR, Allen SM, Alexander A, Brash DE, Grossman D: UVB-induced apoptosis drives clona expansion during skin tumor development. Carcinogenesis 2005, 26:249-257

10. Halliday GM: Inflammation, gene mutation and photoimmunosuppression in response to UVR-induced oxidative damage contributes to photocarcinogenesis. Mutat Res 2005, 571:107-120

11. Melnikova VO, Ananthaswamy HN: Cellular and molecular events leading to the development of skin cancer. Mutat Res 2005, 571: 91-106

12. Lin WW, Karin M: A cytokine-mediated link between innate immunity, inflammation, and cancer. J Clin Invest 2007, 117:1175-1183

13. Jiang $\mathrm{W}$, Ananthaswamy $\mathrm{HN}$, Muller HK, Kripke ML: p53 protects against skin cancer induction by UV-B radiation. Oncogene 1999, 18:4247-4253

14. van Kranen HJ, Westerman A, Berg RJ, Kram N, van Kreijl CF, Wester PW, de Gruijl FR: Dose-dependent effects of UVB-induced skin carcinogenesis in hairless p53 knockout mice. Mutat Res 2005 571:81-90 
15. Hu Y, Baud V, Delhase M, Zhang P, Deerinck T, Ellisman M, Johnson $\mathrm{R}$, Karin M: Abnormal morphogenesis but intact IKK activation in mice lacking the IKK $\alpha$ subunit of $I_{K B}$ kinase. Science 1999, 284:316-320

16. Takeda K, Takeuchi O, Tsujimura T, Itami S, Adachi O, Kawai T, Sanjo $\mathrm{H}$, Yoshikawa K, Terada N, Akira S: Limb and skin abnormalities in mice lacking IKK $\alpha$. Science 1999, 284:313-316

17. Liu B, Park E, Zhu F, Bustos T, Liu J, Shen J, Fischer SM, Hu Y: A critical role for l\{kappa\}B kinase \{alpha\} in the development of human and mouse squamous cell carcinomas. Proc Natl Acad Sci U S A 2006, 103:17202-17207

18. Maeda G, Chiba T, Kawashiri S, Satoh T, Imai K: Epigenetic inactivation of IkappaB Kinase-alpha in oral carcinomas and tumor progression. Clin Cancer Res 2007, 13:5041-5047

19. Marinari B, Moretti F, Botti E, Giustizieri ML, Descargues P, Giunta A, Stolfi C, Ballaro C, Papoutsaki M, Alema S, Monteleone G, Chimenti S, Karin M, Costanzo A: The tumor suppressor activity of IKKalpha in stratified epithelia is exerted in part via the TGF-beta antiproliferative pathway. Proc Natl Acad Sci U S A 2008, 105:17091-17096

20. Marinari B, Ballaro C, Koster MI, Giustizieri ML, Moretti F, Crosti F, Papoutsaki M, Karin M, Alema S, Chimenti S, Roop DR, Costanzo A: IKKalpha is a p63 transcriptional target involved in the pathogenesis of ectodermal dysplasias. J Invest Dermatol 2009, 129:60-69

21. Descargues P, Sil AK, Sano Y, Korchynskyi O, Han G, Owens P, Wang XJ, Karin M: IKKalpha is a critical coregulator of a Smad4-independent TGFbeta-Smad2/3 signaling pathway that controls keratinocyte differentiation. Proc Natl Acad Sci USA 2008, 105 2487-2492

22. Liu B, Xia X, Zhu F, Park E, Carbajal S, Kiguchi K, DiGiovanni J, Fischer SM, Hu Y: IKKalpha is required to maintain skin homeostasis and prevent skin cancer. Cancer Cell 2008, 14:212-225

23. Park E, Zhu F, Liu B, Xia X, Shen J, Bustos T, Fischer SM, Hu Y: Reduction in IkappaB kinase alpha expression promotes the development of skin papillomas and carcinomas. Cancer Res 2007 67:9158-9168

24. Li N, Karin M: lonizing radiation and short wavelength UV activate NF-kappaB through two distinct mechanisms. Proc Natl Acad Sci USA 1998, 95:13012-13017

25. Liu B, Yang Y, Chernishof V, Loo RR, Jang H, Tahk S, Yang R, Mink S, Shultz D, Bellone CJ, Loo JA, Shuai K: Proinflammatory stimuli induce IKKalpha-mediated phosphorylation of PIAS1 to restrict inflammation and immunity. Cell 2007, 129:903-914

26. Berton TR, Mitchell DL, Fischer SM, Locniskar MF: Epidermal proliferation but not quantity of DNA photodamage is correlated with UV-induced mouse skin carcinogenesis. J Invest Dermatol 1997, 109:340-347

27. Ananthaswamy HN, Loughlin SM, Cox P, Evans RL, Ullrich SE, Kripke ML: Sunlight and skin cancer: inhibition of p53 mutations in UVirradiated mouse skin by sunscreens. Nat Med 1997, 3:510-514

28. Guttridge DC, Albanese C, Reuther JY, Pestell RG, Baldwin AS Jr: NF-kappaB controls cell growth and differentiation through transcriptional regulation of cyclin D1. Mol Cell Biol 1999, 19:5785-5799

29. Melnikova VO, Pacifico A, Chimenti S, Peris K, Ananthaswamy HN: Fate of UVB-induced p53 mutations in SKH-hr1 mouse skin after discontinuation of irradiation: relationship to skin cancer development. Oncogene 2005, 24:7055-7063

30. Hu Y, Baud V, Oga T, Kim KI, Yoshida K, Karin M: IKK $\alpha$ controls formation of the epidermis independently of NF- $\kappa$ B. Nature 2001, 410:710-714

31. Chen K, Iribarren P, Hu J, Chen J, Gong W, Cho EH, Lockett S, Dunlop NM, Wang JM: Activation of Toll-like receptor 2 on microglia promotes cell uptake of Alzheimer disease-associated amyloid beta peptide. J Biol Chem 2006, 281:3651-3659
32. Mitchell DL, Nairn RS: The biology of the (6-4) photoproduct. Photochem Photobiol 1989, 49:805-819

33. Leibeling D, Laspe P, Emmert S: Nucleotide excision repair and cancer. J Mol Histol 2006, 37:225-238

34. Wheeler DL, Martin KE, Ness KJ, Li Y, Dreckschmidt NE, Wartman M, Ananthaswamy HN, Mitchell DL, Verma AK: Protein kinase C epsilon is an endogenous photosensitizer that enhances ultraviolet radiationinduced cutaneous damage and development of squamous cell carcinomas. Cancer Res 2004, 64:7756-7765

35. Cao C, Lu S, Jiang Q, Wang WJ, Song X, Kivlin R, Wallin B, Bagdasarian A, Tamakloe T, Chu WM, Marshall J, Kouttab N, Xu A, Wan Y: EGFR activation confers protections against UV-induced apoptosis in cultured mouse skin dendritic cells. Cell Signal 2008, 20:1830-1838

36. Li ZW, Chu W, Hu Y, Delhase M, Deerinck T, Ellisman M, Johnson R, Karin $\mathrm{M}$ : The IKK $\beta$ subunit of $I_{\kappa} B$ kinase (IKK) is essential for nuclear factor $\kappa \mathrm{B}$ activation and prevention of apoptosis. J Exp Med 1999, 189:1839-1845

37. Correa RG, Matsui T, Tergaonkar V, Rodriguez-Esteban C, IzpisuaBelmonte JC, Verma IM: Zebrafish IkappaB kinase 1 negatively regulates NF-kappaB activity. Curr Biol 2005, 15:1291-1295

38. Zandi E, Rothwarf DM, Delhase M, Hayakawa M, Karin M: The $I_{\kappa} \mathrm{B}$ kinase complex (IKK) contains two kinase subunits. IKK $\alpha$ and IKK $\beta$, necessary for $I_{\kappa} B$ phosphorylation and NF- $\kappa B$ activation. Cell 1997 91:243-252

39. Mercurio F, Zhu H, Murray BW, Shevchenko A, Bennett BL, Li J, Young DB, Barbosa M, Mann M, Manning A, Rao A: IKK-1 and IKK-2 cytokine-activated $I_{\kappa} \mathrm{B}$ kinases essential for NF- $\kappa \mathrm{B}$ activation. Science 1997, 278:860-866

40. Fujimoto H, Sangai T, Ishii G, Ikehara A, Nagashima T, Miyazaki M, Ochiai A: Stromal MCP-1 in mammary tumors induces tumor-associated macrophage infiltration and contributes to tumor progression. Int J Cancer 2009, 125:1276-1284

41. Du S, Hiramatsu N, Hayakawa K, Kasai A, Okamura M, Huang T, Yao J, Takeda M, Araki I, Sawada N, Paton AW, Paton JC, Kitamura M: Suppression of NF-kappaB by cyclosporin a and tacrolimus (FK506) via induction of the C/EBP family: implication for unfolded protein response. J Immunol 2009, 182:7201-7211

42. Zhu F, Xia X, Liu B, Shen J, Hu Y, Person M, Hu Y: IKKalpha shields 14-3-3sigma, a G(2)/M cell cycle checkpoint gene, from hypermethylation, preventing its silencing. Mol Cell 2007, 27:214-227

43. Balmain A, Pragnell IB: Mouse skin carcinomas induced in vivo by chemical carcinogens have a transforming Harvey-ras oncogene. Nature 1983, 303:72-74

44. Van Waes C, Yu M, Nottingham L, Karin M: Inhibitor-kappaB kinase in tumor promotion and suppression during progression of squamous cell carcinoma. Clin Cancer Res 2007, 13:4956-4959

45. Luo JL, Kamata H, Karin M: The anti-death machinery in IKK/NFkappaB signaling. J Clin Immunol 2005, 25:541-550

46. Sharma SD, Meeran SM, Katiyar SK: Dietary grape seed proanthocyanidins inhibit UVB-induced oxidative stress and activation of mitogen-activated protein kinases and nuclear factor-kappaB signaling in in vivo SKH-1 hairless mice. Mol Cancer Ther 2007, 6:995-1005

47. Syed DN, Afaq F, Kweon MH, Hadi N, Bhatia N, Spiegelman VS Mukhtar H: Green tea polyphenol EGCG suppresses cigarette smoke condensate-induced NF-kappaB activation in normal human bronchial epithelial cells. Oncogene 2007, 26:673-682

48. Adhami VM, Afaq F, Ahmad N: Suppression of ultraviolet B exposuremediated activation of NF-kappaB in normal human keratinocytes by resveratrol. Neoplasia 2003, 5:74-82

49. Koster MI, Dai D, Marinari B, Sano Y, Costanzo A, Karin M, Roop DR: p63 induces key target genes required for epidermal morphogenesis. Proc Natl Acad Sci USA 2007, 104:3255-3260 